than I7 per cent. occur the population is termed blond, where more than 30 per cent. dark.

According to this grouping the two extremes are the Swedish ( 3 per cent. brunettes) and southern Italy (70 per cent.). From this point of view the map showed that north Europe was mainly blond, South Europe dark, and Central Europe intermediate. He traced the southern limit of the blond races through the various countries, showing that it nowhere reached below the 5oth parallel in Central Europe, and below 55th parallel in Britain and Russia. The northern limit of the dark peoples is more irregular. In the intermediate zone blond areas are rare (one of these occur in south England, i.e. Berkshire, Oxfordshire, Hampshire, Sussex and Middlesex), dark areas fairly numerous, but individually very small. Intermediate areas in the blond zone are only found in the British Isles, but in the dark zone are fairly frequent in western Europe.

From these data and certain other considerations relating to shape of face and nose, character of hair, \&c., Dr. Deniker had been confirmed in his theory that the present population of Europe is composed of six main races. These he proceeded to enumerate, giving their typical characteristics, tracing their positions throughout the map, and indicating the proportions in which they had intermingled to form the existing populations of the various countries. The following is an abbreviated sketch of his classification :-

(I) A race, blond, wavy-haired, long-headed, very tall, with long face, a straight prominent nose; the northern race, so called because its representatives are confined almost exclusively to North Europe. This is the Cymric race of Broca, the Germanic or Reihengräber race of German authors, the Teutonic race of Ripley, or the Homo Europaeus of Lapouge.

With this race is connected a subrace, blond or intermediate, straight-haired, medium-headed, of tall or medium stature, angular face, and retroussé nose, the subnorthern race, found in the neighbourhood of the northern.

(2) A race blond, straight-haired, moderately shortheaded, and of short stature, broad square face, nose often retroussé; the Eastern race, so named since its principal home is in eastern Europe.

Connected with this is a subrace, blond or intermediate, medium-headed, of very short stature, named the Vistulian race, occurring in Poland, parts of Prussia, and probably Saxony and Silesia.

(3) A race dark, hair sometimes curly, long-headed, of very short stature, straight or retroussé nose; the Iberoinsular race. This is the Mediterranean race, or Homo Mediterraniensis of certain authors, found chiefly in the Iberian Peninsula and the islands of the western Mediterranean.

(4) A race dark, very short and round headed, of short stature, round face, broad nose, and thick-set body; the Cevenole or western race. This type occurs in its greatest purity in the extreme west of Europe, though found sporadically elsewhere. This is the race called variously by other authors Celtic, Celto-Ligurian, Celto-Slavonic, Sarmatian, Rhetian, Ligurian, or Homo Alpinus.

(5) A race very dark, moderately long-headed, and fairly tall; the Littoral, or Atlanto-Mediterranean race, situated on the coast of the Mediterranean, from Gibraltar to the Tiber, and in occasional groups on the Atlantic Littoral, but never more than 150 miles from the sea.

(6) A race dark, short-headed, tall, nose slender and straight or arched; the Adriatic or Dinaric race, which is found grouped round the northern Adriatic, particularly in Bosnia, Dalmatia, Croatia, and the centre of the Balkan Peninsula, but found also sporadically and with somewhat modified characteristics in Central Europe.

With the last two races are connected two secondary races, which are perhaps no more than types, produced by the admixture of the two former with each other or with the northern, subnorthern, and western races.

(a) The north-western, long- or medium-headed, situated between the northern and Atlanto-Mediterranean saces, spread chiefly in Ireland.

(b) The sub-Adriatic, moderately short-headed, more rarely short-headed, of medium stature, found in many parts of Central Europe, probably the result of admixture between the Adriatic and subnorthern and western races.

\section{REPORT OF THE SURVEY OF INDIA}

THE Indian Survey report is a full record of useful work and widespread progress, but it lacks some of the interest which used to attach formerly to the very varied character of the work undertaken by the Survey department. The scientific section of the report is included within the limits of a few pages; and the narratives of individual surveyors (which always formed a most interesting chapter or two) have entirely disappeared.

The main work of the department, now, is the revision of old mapping in districts which have been sorely in need of such revision for many years. The plains of India, in fact, are being re-surveyed, and, on the whole, the work of the department is increasing, rather than diminishing, on purely utilitarian lines. It would almost seem as if the days of Indian geodetic triangulation, which once took such a strong lead amongst the scientific triangulations of the world, were numbered. Only one first-class series is in progress at present, and this is to connect the great meridional Mandalay series of Burma with a future extension following the Salwin valley. It is, however, satisfactory that the practice and training necessary for surveyors in this class of work is well maintained so far, for it is impossible to say what the future may demand in the way of similar extensions in Persia, Tibet, or even in China.

One subject of special interest dealt with in the report is the deflection of gravity. In I90I a theory was advanced by Major Burrard that defiections of gravity in India could be classified by regions. Astronomical determinations of latitude have therefore been carried systematically through considerable arcs to prove whether this theory were sound The results undoubtedly support Major Burrard's prediction, and it is expected that the substitution of this regional law for the old theory of local attraction will exercise a profound influence on future investigations.

The report on geographical or reconnaissance surveys (on the scale of $1 / 500,000$ ) includes an out-turn of 38,000 square miles of survey of this class by one native assistant in western Tibet. This seems a remarkably large out-turn for one surveyor to secure during the progress of a " shooting expedition " ; but it is only one instance amongst many of the remarkable capacity of well trained native explorers for work of this nature. In reasonably easy country there seems to be hardly any limit to their power of producing fairly accurate geographical maps so long as they have a few fixed points to work upon.

In this connection it is well to note the remarks of the Surveyor-General (Colonel St. G. Gore) on the difficulty that constantly faces him of finding qualified native assistants to meet the demands of military or political missions or geographical expeditions. He most justly observes that in the first place it is difficult to find the men who possess the necessary qualifications, and in the second that, having found them, it is impossible to train them efficiently in country which is unsuitable for instruction. It is due to a combination of natural aptitude with perfect educational environment that the native explorer of the Indian Survey becomes so extraordinarily efficient as a topographer. If these men are wanted (and they are wanted) for Imperial duty over half of the continents of Africa and Asia, it seems but fair that the Imperial Treasury should contribute something towards maintaining a sufficient staff to meet all demands.

T. H. H.

\section{UNIVERSITY AND EDUCATIONAL INTE LLIGENCE.}

Cambridge.-The State Medicine Syndicate reports that during the current year there were 57 candidates for the diploma in public health, of whom 34 were successful. For the diploma in tropical medicine and hygiene there were 12 candidates, of whom 8 were successful. The syndicate has resolved to hold two examinations for the latter diploma in 1905 , the first beginning on January 10, the second on August 8.

Applications for the vacant readership in botany (annual stipend $300 l$.) are to be sent to the Vice-Chancellor by Tuesday, November 15 .

Mr. R. H. Lock, late Frank Smart student in botany, has been elected to a Drosier fellowship at Gonville and 
Caius College. Dr. A. C. Haddon, university lecturer in ethnology, has been elected to a senior fellowship at Christ's College.

A DEPARTMENT of experimental psychology has been established, says Science, in the Western University of Pennsylvania, under the charge of Dr. Edmund B. Huey.

THE new medical buildings of the University of Liverpool will be opened by the Chancellor, Lord Derby, on Saturday, November 12, and on the same day Lord Kelvin will formally open the new George Holt Physics Laboratory.

THE council of the University of Liverpool has just appointed Dr. J. H. Grindley lecturer in engineering, $\mathrm{Mr}$. A. Leitch assistant lecturer in engineering, and $\mathrm{Mr}$. G. E. Piper demonstrator in applied mechanics and engineering design and drawing.

WE regret to learn of the death of Prof. D. W. Fiske on September 17 . The bulk of his estate, including the great book collections, has been left to Cornell University. It is stated in Scicnce that the bequest amounts to between $100,000 l$. and $200,000 \mathrm{l}$.

DR. E. G. Coker, of the McGill University, Montreal, has been appointed to the professorship of mechanical engineering and applied mathematics at the City and Guilds Technical College, Finsbury, vacated by the appointment of Prof. Dalby to the professorship of engineering at the institute's Central Technical College.

Mr. Francis Galton, F.R.S., has endowed a research fellowship in the University of London for the promotion of the study of " national eugenics," defined as "the study of the agencies under social control that may improve or impair the racial qualities of future generations either physically or mentally." The fellowship is of the annual value of $250 l$., is tenable for one year in the first instance, and is renewable for two subsequent years. The person appointed to the fellowship will be required to devote the whole of his time to the study of the subject, and in particular to carry out investigations into the history of classes and families, and to deliver lectures and publish memoirs on the subject of his investigations.

THE report on the work of the department of technology of the City and Guilds of London Institute for the session 1903-4 has now been published. The general introduction to the report points out that the encouragement now offered by the Board of Education to the teaching of technology is among the causes contributing to the increase in the number of students in the institute's registered classes. Compared with the figures given in last year's report, those for the past session show a decided improvement. In the different branches of technology, the number of students in November last attending classes in the United Kingdom was 41,089 as compared with 38,638 in the previous year, and the number of examinees was $20,05 \mathrm{I}$ as against 17,989 . The closer connection of the work of the department with that of the Board of Education is shown, also, not only by the recognition of the City and Guilds of London Institute as an organisation for the inspection of classes in technology, manual training, and domestic economy, but also by the stamping by the Board of Education of full certificates granted by the institute to students who pass in technology and have "qualified in the cognate science or art subjects required by the institute." It is interesting to find that the question of arranging courses of instruction adapted to the requirements of operatives engaged in shipbuilding is under consideration; it is intended to extend the syllabus in ship carpentry and joinery so as to make it suitable for artisans engaged in other branches of the industry. Care is to be taken not to overlap the syllabus in naval architecture of the Board of Education, and it is expected that the new examination will appeal to a different class of candidates from those who have hitherto presented themselves for examination. It should be noted that the department of technology of the institute occupies an intermediate position between the central and local education authorities and the several trade societies. The latter bodies have shown a growing interest in technical instruction, and year by year the department has grown into more intimate relationship with these trade organisations.

NO. I827, VOL. 71$]$

\section{SOCIETIES AND ACADEMIES.} LONDON.

Entomological Society, October 19.-Prof. E. B. Poulton, F.R.S., president, in the chair.-Dr. T. A. Chapman exhibited a series of Lozopera deaurana, Peyr., bred last spring at Hyères, a species regarded as lost, or mythical, until he re-discovered it three years ago at lie Ste. Marguerite, Cannes. $\mathrm{He}$ also exhibited on behalf of Mr. Hugh Main a specimen of Pieris brassicae, the anterior and posterior wings of which had been symmetrically injured, probably by the girdle when in the pupal stage--Mr. G. C. Champion exhibited specimens of Nothorrhina muricata, Dalm., from Las Navas, Spain, found trapped in the earthenware cups used to collect the exuding resin on the trunks of pines.Mr. H. St. J. Donisthorpe exhibited specimens of the rare beetle, Cis bilamellatus, Wood, taken at Shirley on October Io last.-Mr. W. J. Lucas exhibited a $O$ specimen of the rare dragonfly Agrion armatum. He said that a $\delta$ and a $O$ were taken in the Broads by Mr. F. B. Browne last year, and this year about ten more, probably all $q q$, were taken in the same district. Besides these there are possibly no other examples in Britain. It is quite distinct from our other six blue Agrionines in form and colouring.-Mr. W. J. Kaye exhibited five specimens of Dianthoecia luteago, var. ficklini, from North Cornwall, taken during the first week of July, I90I, and remarked that while the typical $D$. luteago of the Continent was tolerably constant, wherever it occurred in Britain it assumed a special local form.-Prof. E. B. Poulton, F.R.S., exhibited a number of specimens of the genus Sphecodes, five species in all, and of Ocyptera brevicornis, a Tachinid, their mimetic fly, illustrative of Mr. Edward Saunders's recent paper on the aculeate Hymenoptera from the Balearic Islands and Spain.-Mr. C. A. J. Rothney sent for exhibition a series of the Indian ant Myrmicaria fodiens, from a colony established thirty-two years in the big banyan tree in Barrackpore Park; and specimens of Monomorium salomonis, Lin., and Solenopsis geminata, Fab., successfully encouraged in Madras as a protection against white ants-termites.-Mr. E. E. Green exhibited a spider from Ceylon mimetic of some coccinellid beetle, at present unidentified.-Colonel J. W. Yerbury exhibited specimens, and read notes upon, deer gadflies taken by him this year in Scotland.

Literary and Philosophical Society, October 18. - Prof. W. Boyd Dawkins, F.R.S., president, in the chair.-Dr. W. A. Bone read a paper entitled "The Mode of Combustion of Hydrocarbons," in which he gave an account of researches carried out by Messrs. R. V. Wheeler and W. E. Stockings and himself, at the Owens College, on the slow combustion of hydrocarbons below their ignition points. Dr. Charles H. Lees exhibited a modification of the U-tube used in electrolysis which he had devised, and which diminishes to about one-half the correction for pressure due to the coiumn of liquid in the unsealed limb of the tube.

\section{PARIS.}

Academy of Sciences, October 24.-M. Mascart in the chair.-Stereoscopy without a stereoscope: J. Violle. In a camera, furnished with two objectives, directly in front of the plate is placed a grating, ruled with 100 black lines to the inch. The negative from this contains the two sets of images, each crossed with a set of fine bands. When this is looked at through a similar ruled plate the picture appears in relief.-On the modifications of glycolysis in the capillaries caused by local modification of the temperature: R. Lepine and $M$. Boulud. The experiments were made on dogs. Relatively to the arterial blood, the venous blood of the warmer part always contains a little more sugar. In the case of the paw kept cool, this difference is increased to about double, and is in the same direction. On integral functions of finite order: L. Leau.-On certain partial differential equations of the second order : S. Bernstein.-On the period of antennæ of different forms: C. Tissot. On account of the high value of the deadening, the rotating mirror method does not give accurate figures for the period, and the author describes another method which is free from this objection. It is 